\title{
A Strategy to Defeat the Corona Virus (COVID-19) with Passive Immunotherapy (PIT)
}

\author{
Abraham Karpas ${ }^{1 *}$, Douglas R Bainbridge ${ }^{2}$ and Steve Ash ${ }^{3}$ \\ ${ }^{1}$ Emeritus, Department of Haematology, Clinical School, University of Cambridge, UK \\ ${ }^{2}$ Emeritus, Consultant in Clinical Immunology, Royal London Hospital, UK \\ ${ }^{3}$ Emeritus, Consultant Physician, Ealing General Hospital, UK
}

Of the most important recently discovered disease-causing zoonotic infections of man, the primate retroviruses HIV1 which gave rise to AIDS and its minor variant HIV-2 are of global importance. HIV-1 started to infect man around the world in the mid-70s and killed hundreds of thousands even before it was isolated and identified.

Since a French team from the Institute Pasteur in Paris isolated the causative agent [1] and provided the evidence that it is cytopathic to CD4+ T-cells of the immune system [2] thereby explaining why AIDS developed, an enormous effort and vast sums of money have been spent over the past 35 -years on developing a vaccine. But all efforts and investments have failed. The reason: Because HIV is a retrovirus, through its reverse transcriptase making a DNA copy of its RNA genome that integrates into the DNA of infected cells. These are not instantly killed by the virus, thus maintaining an infectious state for life [3].

Early on we were able to establish that although both AIDS patients and healthy HIV-infected individuals tested positive for anti-HIV antibodies, AIDS patients had a far lower level of antibodies and more significantly, were devoid of antibodies that were capable of neutralising the virus.

During the $80 \mathrm{~s}$ and into the 90s there were no effective anti-HIV drugs, so this led us to initiate a trial of passive immunotherapy in Cambridge in 1985 [4] and later in London. Plasma from healthy HIV-positive individuals who still had a high number of CD4+ T-cells (which we found to correlate with high levels of neutralising antibodies to the virus) was collected by plasmapheresis and given by infusion to patients with advanced AIDS [5-7]. Right from the beginning infusion of the plasma improved their well-being. Subsequent double-blind controlled studies from the USA [8] and France [9] confirmed the long-term benefit. However as HIV causes a life-long infection with AIDS patients needing treatment continuously by monthly transfusions and we were dealing with a limited number of plasma donors, many of the donors were required to donate repeatedly at monthly or bi-monthly intervals. Plasmapheresis rather than whole-blood donation was used to avoid depleting donors of red and white blood cells, but we felt it essential to determine whether repeated donation had other detrimental effects. In the event detailed study of the various lymphocyte populations showed none [10]. Over several years passive immunotherapy for AIDS patients was given both at the Royal London Hospital by one of us and at Ealing General Hospital by Dr S. Ash.

Several reports have appeared of successful PIT following a single infusion after Ebola infections in Africa [11]; but here it was of restricted scope, because most Ebola-infected individuals die of the infection, greatly limiting the supply of blood/plasma available to use in treatment.

The corona viruses are transient RNA viruses; it appears that once an infected individual recovers he/she becomes virus-free and immune. Though very little is yet known about neutralising antibodies in SARS-Covid-19, it is not unreasonable to suppose that in this disease also corona-infected individuals who recover will have developed protective antibodies. In fact in a recent report 10 very advanced corona patients were treated with a single $200 \mathrm{ml}$ dose of plasma obtained from individuals who had recovered from the infection and showed impressive clinical improvement [12]. We have been told of a similar outcome from passive immunotherapy in Germany (Dr. Z Lichtenstein, personal communication).

In the absence of generally effective drugs or the prospect of a vaccine in the near future, we suggest in broad terms the following protocol to try and stop the virus from killing so many people world-wide and causing such widespread economic and social damage: There are some ten times more healthy corona virus-recovered individuals than deaths; and those who recover should have anti-viral immunity, amongst which in all probability, neutralising antibodies in their blood

*Corresponding author: Abraham Karpas, Emeritus, Department of Haematology, Clinical School, University of Cambridge, UK

Received: April 18, 2020

Accepted: April 28, 2020

Published online: April 30, 2020

Citation: Karpas A, Bainbridge DR, Ash S (2020) A Strategy to Defeat the Corona Virus (COVID-19) with Passive Immunotherapy (PIT). Clin J HIV AIDS 4(1):44-45 
against the virus. It would not be unreasonable to ask the younger individuals to donate blood. Blood can be stored for a month; every medical centre could collect such donations to create a bank of hyperimmune blood/plasma, which could be provided firstly to the severely ill patients as a blood or plasma transfusion with a matching blood group; and thereafter to newly infected individuals developing clinical symptoms. Hopefully the majority of the sick patients receiving PIT will recover and those in the early phase of the disease will recover more quickly.

Treatment with passive immunotherapy might be expected to fail, at least theoretically, in certain situations: [1] if a given donor's level of protective antibodies has dropped too low, due to the normal half-life of antibodies. The simplest thing will then be to give PIT from another donor; [2] if a given donor's immunity is based on some other mechanism than neutralising antibodies. As an example, the T- and NK-like cellular responses to SARS-Covid-19 are, as far as we are aware, completely unknown and so far unstudied. Again, the simplest thing will be to give PIT from a different donor. In this regard being able to determine reliably the anti-viral activity of any potential donor plasma will unquestionably be a great advantage.

Interestingly, there is a recent Italian scheme by blood transfusion services in the localities of Lombardy most severely affected by Covid-19 to screen all regular normal blood donations and test for viral neutralising antibody, on the grounds that asymptomatic donors are very likely to have been infected and, as asymptomatic, to be more strongly immune than individuals recovering from the disease. In this way it is hoped to build up a bank of hyper immune plasma for use in emergency.

\section{References}

1. Barre-Sinnoussi F, Cherann JC, Rey F, et al, (1983) Isolation of a T-lymphotropic retrovirus from a patient at risk of Acquired Immune deficiency Syndrome (AIDS). Science 220: 868-871.

2. Klazmann D, Barre-Sinoussi F, Nugeyere MT, et al. (1984) Selec- tive Tropism of Lymphadenopathy associated retrovirus (LAV) for helper-inducer T-lymphocytes. Science 225: 59-63.

3. Karpas A (2004) Human retroviruses in leukaemia and AIDS: Reflection on their discovery, biology and epidemiology. Biol Rev Camb Philos Soc 79: 911-933.

4. Karpas A, Gillson W, Bevan PC, et al. (1985) Lytic infection by a Lytic AIDS Virus and the Development of a Rapid Cell Test for Anti- Viral antibodies. Lancet 2: 695-697.

5. Karpas A, Hill F, Youle, et al. (1988) Effect of Passive immunisation in patients with acquired immunodeficiency syndrome. Proc Nat Acad Sci USA 85: 9234-9237.

6. Karpas A, Hewlett IK, Hill F, et al. (1990) Polymerase Chain reaction evidence for human immunodeficiency 1 neutralisation by Passive immunisation in Patients with AIDS and AIDS related Complex. Proc Nat Acad Sci USA 87: 613-617.

7. Blick G, Scott WF, Cook SW, et al. (1998) Passive immunotherapy in advanced HIV infection and therapeutic plasmapheresis in asymptomatic HIV-positive Individuals: A four year clinical experience. Biotherapy 11: 7-14.

8. Levy J, Youvan T, Lee ML (1990) Passive hyperimmune plasma therapy in the treatment of of acquired immunodeficiency syndrome: Results of a 12 months double blind control trial. Blood 84: 2130-2135.

9. Vittecoq D, Chevret S, Morand-Joubert L, et al. (1995) Passive immunotherapy in AIDS: A double blind randomised study based on the transfusions of plasma rich in anti-human immunodeficiency 1 antibodies vs Transfusion of Seronegative Plasma. Proc Nat Acad Sci USA 92: 1195-1199.

10. Bainbridge DR, Lowdell MW, Hannet IM, et al. (1997) Can repeated plasma donation by asymptomatic HIV-infected individuals delay the onset of AIDS? Philos Trans R Soc Lond B Biol Sci 352: 763-770.

11. Sahrhr F, Ansumana R, Massaquoi TA, et al. (2017) Evaluation of convalescent whole blood for treating Ebola virus disease in Freetown sierra Leone J. Infect 74: 302-309.

12. Duan K, Liu B, Li C, et al. (2020) Effectiveness of Convalescent Plasma Therapy in Severe COVID-19 Patients. Proc Nat Acad Sci USA, 1-7.

DOI: $10.36959 / 695 / 568$

Copyright: (c) 2020 Karpas A, et al. This is an open-access article distributed under the terms of the Creative Commons Attribution License, which permits unrestricted use, distribution, and reproduction in any medium, provided the original author and source are credited. 